\title{
Comportamento ingestivo diurno de novilhos Nelore recebendo níveis crescentes de suplementação em pastejo de capim-braquiária ${ }^{1}$
}

\section{Robério Rodrigues Silva ${ }^{2}$, Ivanor Nunes do Prado ${ }^{3}$, Fabiano Ferreira da Silva ${ }^{4}$, Vitor Visintin Silva de Almeida ${ }^{5}$, Hermógenes Almeida de Santana Júnior ${ }^{6}$, Augusto César de Queiroz ${ }^{7}$, Gleidson Giordano Pinto de Carvalho ${ }^{4}$, Daniele Soares Barroso ${ }^{2}$}

1 Projeto financiado pelo Banco do Nordeste do Brasil/FUNDEC.

2 DEBI/UESB, Itapetinga, $B A$.

${ }^{3}$ DZO/UEM, Maringá, $P R$.

${ }^{4}$ DTRA/UESB, Itapetinga, $B A$

5 Programa de Pós-graduação em Zootecnia - UFV.

${ }^{6}$ Universidade Estadual do Sudoeste da Bahia - UESB.

${ }^{7}$ DZO/UFV, Viçosa, MG.

RESUMO - Objetivou-se avaliar o comportamento ingestivo diurno de novilhos em pastagem de capim-braquiária submetidos a suplementação energética e proteica. Foram utilizados 40 novilhos Nelore, com peso inicial de 373,7 $\pm 14,9 \mathrm{~kg}$ e 26 meses de idade, distribuídos em quatro níveis de suplementação: mistura mineral, 0,3; 0,6 e 0,9\% do peso vivo de suplementação energética e proteica. Os animais foram observados visualmente por dois períodos de 12 horas; das 6 às 18 h. Os tempos de pastejo, ruminação e ócio sofreram efeito quadrático, e o tempo de cocho efeito linear crescente. Os consumos de matéria seca total não foram alterados pelos níveis de suplementação. O consumo total de matéria seca oriunda da pastagem e todas variáveis relacionadas à fibra em detergente neutro e fibra em detergente ácido decresceram linearmente. O número de mastigações por bolo decresceu linearmente. O número de períodos de pastejo e o tempo por período de cocho aumentaram linearmente. O tempo por período de pastejo decresceu linearmente. O número de períodos de ruminação, número de períodos de ócio e tempo por período de ruminação sofreram efeito quadrático. O número de períodos de cocho sofreu efeito cúbico A suplementação compromete as variáveis relacionadas ao comportamento ingestivo diurno, não só pela quantidade de alimento ingerido, mas também por sua composição e pela razão volumoso:concentrado, portanto, exige atenção no balanceamento de rações.

Palavras-chave: bovinos, etologia, ócio, ruminação

\section{Diurnal ingestive behavior of Nellore steers receiving increasing levels of supplement in brachiaria pasture}

\footnotetext{
ABSTRACT - The objective this study was to evaluate the diurnal ingestive behavior of Nellore steers on Brachiaria grass pasture submitted to protein and energy supplementation. It was used 40 Nellore steers, at initial weight of $373.7 \pm 14.9 \mathrm{~kg}$, and at 26 months of age, distributed in four levels of supplementation:mineral mixture, $0.3,0.6$ and $0.9 \%$ of body weight of energy and protein supplementation. The animals were visually observed by two 12-hour periods from 6:00 a.m. to 06:00 p.m. Grazing, ruminating and idle times had a quadratic effect and the trough time had a linear increase effect. The total dry matter intakes were not affected by the supplementation levels. Total consumption of dry matter from pasture and all the variables related to neutral detergent fiber and acid detergent fiber decreased linearly. The number of chews per bolus linearly decreased. The number of grazing periods and time for feed period increased linearly. The time for grazing period decreased linearly. The number of ruminating periods, number of idle periods and time for rumination period suffered a quadratic effect. The number of trough periods suffered a cubical effect. Supplementation compromises the variables related to diurnal ingestive behavior, not only because of the quantity of ingested food but also because of its composition and because of the roughage:concentrate ratio, therefore, attention on meal balance is required.
}

Key Words: cattle, ethology, resting, ruminating

Recebido em 31/10/2008 e aprovado em 11/9/2009

Correspondências devem ser enviadas para: rrsilva.uesb@hotmail.com 


\section{Introdução}

O consumo de forragem de animais em pastejo é influenciado por três grupos de fatores: os que afetam o processo de digestão, os que afetam o processo de ingestão e aqueles que afetam as exigências nutricionais e a demanda por nutrientes (Berchielli et al., 2006). Um dos problemas existentes na criação de bovinos em pastejo é a variação tanto na quantidade como na qualidade da matéria seca produzida, afetando negativamente a produtividade animal. Neste contexto, a suplementação à pasto tem se constituído uma das principais alternativas de produção de bovinos de corte em pastagens naturais ou cultivadas (Moreira et al., 2003). Nas épocas do ano em que a produção de forragem é mais afetada, a suplementação em pastejo possibilita a obtenção de maiores ganhos de peso por animal e por área (Rocha, 1999).

O sistema de criação de bovinos à pasto é caracterizado por uma série de fatores e suas interações podem afetar o comportamento ingestivo dos animais, comprometendo o seu desempenho e, consequentemente, a viabilidade da propriedade (Pardo et al. , 2003).

O estudo do comportamento ingestivo dos ruminantes pode nortear a adequação de práticas de manejo que venham a aumentar a produtividade e garantir o melhor estado sanitário e longevidade aos animais (Fischer et al., 2002). Segundo Albright (1993), pode-se citar como alguns exemplos práticos: a localização de sistemas automáticos de fornecimento de água e alimentos, o acesso mais fácil à ração, a utilização de dimensões corretas das instalações e equipamentos a fim de evitar a competição por espaço entre os animais, a disponibilidade de sombras e abrigos para garantir aos animais a possibilidade de procurar ambientes que venham a satisfazer as faixas de conforto térmico mais adequadas ao seu bem-estar, e os horários regulares e frequências para distribuição dos alimentos para animais.

Os resultados encontrados na literatura, referentes às alterações provocadas pela suplementação à pasto sobre o comportamento ingestivo dos ruminantes são controversos. Assim, torna-se imprescindível a realização de pesquisas que venham esclarecer o efeito da suplementação sobre o comportamento dos animais em pastejo e seus possíveis reflexos no desempenho animal (Brâncio et al., 2003).

Objetivou-se com este estudo avaliar o comportamento ingestivo diurno de novilhos Nelore em pastagem de Brachiaria brizantha sob suplementação com concentrado.

\section{Material e Métodos}

O experimento foi desenvolvido entre os meses de agosto e novembro de 2006. O trabalho de campo foi implantado numa área de 52 ha, dividida em oito piquetes de aproximadamente 6,3 ha cada, formada de Brachiaria brizantha cultivar Marandu subdivididas em formato de pizza com aguada central.

Foram utilizados 40 novilhos da raça Nelore com peso inicial de 373,7 $\pm 14,9$ kg e 26 meses de idade distribuídos em delineamento inteiramente casualizado, com quatro níveis de suplementação (sal mineral e suplementação energética e proteica nos níveis 0,3; 0,6 e 0,9\% do peso vivo), cada um avaliado com 10 repetições. O período experimental foi de 98 dias, sendo 14 deles destinados à adaptação dos animais ao manejo e às dietas experimentais.

A pastagem foi avaliada a cada 28 dias. Para estimar a disponibilidade de matéria seca (MS), foram tomadas 12 amostras por piquete, cortadas ao nível do solo com um quadrado de $0,25 \mathrm{~m}^{2}$, conforme metodologia descrita por McMeniman (1997). Foi adotado o método de lotação contínua com mesma carga animal. Foram utilizados oito piquetes, diferidos no início de maio. Para reduzir a influência da variação de biomassa entre piquetes, os novilhos permaneceram em cada piquete por sete dias e, após esse período, foram transferidos para outro, em um sentido preestabelecido de forma aleatória.

As estimativas de biomassa residual diária (BRD) de matéria seca foram realizadas nos quatro piquetes, conforme o método da dupla amostragem (Wilm et al., 1994). Antes do corte, foi estimada visualmente a matéria seca da biomassa da amostra. Utilizou-se os valores das amostras cortadas e estimadas visualmente quando foi jogado 70 vezes o quadrado e, posteriormente, calculada a biomassa de forragem expressa em $\mathrm{kg} / \mathrm{ha}$ pela equação proposta por Gardner (1986).

Dentro de cada piquete foi construído um cercado para que servisse de gaiola de exclusão. O acúmulo de MS, nos diferentes períodos experimentais, foi calculado multiplicando-se o valor da taxa de acúmulo diário (TAD) de MS pelo número de dias do período.

A estimativa da TAD foi realizada pela equação proposta por Campbell(1966):

$$
\mathrm{TAD}_{\mathrm{J}}=\left(\mathrm{G}_{\mathrm{i}}-\mathrm{F}_{\mathrm{i}-1}\right) / \mathrm{n}
$$

em que: $\mathrm{TADj}$ = taxa de acúmulo de matéria seca diária no período j, em kgMS/ha/dia; $G_{i}=$ matéria seca final média dos quatro piquetes vazios no instante $\mathrm{i}$, em $\mathrm{kg} \mathrm{MS} / \mathrm{ha} ; \mathrm{F}_{\mathrm{i}-1}=$ matéria seca inicial média presente nos piquetes vazios no instante $\mathrm{i}-1$, em $\mathrm{kg} \mathrm{MS} / \mathrm{ha}$; $\mathrm{n}$ = número de dias do período j. 
A taxa de lotação (TL) foi calculada considerando a unidade animal (UA) como sendo $450 \mathrm{~kg}$ de PV, utilizando-se a seguinte fórmula:

$$
\mathrm{TL}=(\mathrm{UAt}) / a ́ r e a
$$

em que: $\mathrm{TL}=$ taxa de lotação, em UA/ha; UAt = unidade animal total; Área = área experimental total, em ha.

A oferta de forragem (OF) foi calculada de acordo com Prohmannl(2004):

$$
\mathrm{OF}=\left\{(\mathrm{BRD} * \text { área }+\mathrm{TAD} * \text { área }) / \mathrm{PV}_{\text {total }}\right\} * 100
$$

em que: $\mathrm{OF}$ = oferta de forragem, em kg MS/100 kg PV/dia; $\mathrm{BRD}=$ biomassa residual total, em $\mathrm{kg}$ de MS/ha/dia; $\mathrm{TAD}$ = taxa de acúmulo diário, em kg MS/ha/dia; PV = peso vivo dos animais, em $\mathrm{kg} / \mathrm{ha}$.

Os animais foram pesados no início e no final do experimento e foram realizadas também pesagens intermediárias, a cada 28 dias, para ajuste do fornecimento do suplemento. As pesagens foram precedidas por jejum alimentar de 12 horas.

A suplementação foi fornecida diariamente em cochos plásticos sem cobertura. O suplemento foi oferecido uma única vez ao dia e sempre no mesmo horário (10 h).

Para estimar a produção fecal, utilizou-se o óxido crômico como indicador externo, fornecido diariamente às $9 \mathrm{~h}$ em dose única de $10 \mathrm{~g} /$ dia durante 12 dias com sete dias para adaptação e regulação do fluxo de excreção do marcador e

Tabela 1 - Composição em ingredientes dos concentrados

\begin{tabular}{lcccc}
\hline Ingrediente (\%) & \multicolumn{4}{c}{ Nível de suplementação (\%) } \\
\cline { 2 - 5 } & 0,0 & 0,3 & 0,6 & 0,9 \\
\hline Fubá de milho & - & 89,98 & 95,11 & 87,98 \\
Farelo de soja & - & - & - & 10,40 \\
Ureia $^{\text {Sal mineral }}{ }^{1}$ & - & 5,00 & 2,44 & 0,06 \\
\hline
\end{tabular}

${ }^{1}$ Composição: cálcio - 13,2\%; fósforo - 4,4\%; magnésio - 0,5\%; enxofre - 1,2\%; sódio - 17,8\%; selênio -0,0012\%; cobre - 0,125\%; zinco - 0,03\%; manganês $0,075 \%$; iodo - 0,005\%; cobalto - $1,07 \%$. cinco dias para coleta das fezes. As fezes foram coletadas uma vez ao dia no momento da administração do indicador, diretamente da ampola retal e, após, armazenadas em câmara fria a $-10^{\circ} \mathrm{C}$. As amostras de fezes foram analisadas por espectrofotometria de absorção atômica (EAA) para dosagem de cromo, conforme Williams et al. (1962). Estimou-se a produção fecal, conforme a equação abaixo:

$$
\mathrm{PF}=\mathrm{OF} / \mathrm{COF}
$$

em que $\mathrm{PF}=$ produção fecal diária (g/dia); OF = óxido crômico fornecido (g/dia) e COF = concentração de óxido crômico nas fezes (g/gMS).

Para determinação do indicador interno, fibra em detergente ácido indigestível (FDAi), as amostras da forragem, das fezes e dos concentrados foram incubadas no rúmen de quatro animais fistulados por $144 \mathrm{~h}$, tendo o resíduo sido assumido como indigestível.

O consumo de MS foi estimado através da equação descrita por Kabeya et al. (2002):

$$
\mathrm{CMS}=\{[(\mathrm{PF} * \mathrm{CIFZ})-\mathrm{IS}] / \mathrm{CIFR}\}+\mathrm{CMSS}
$$

em que CMS = consumo estimado de matéria seca ( $\mathrm{kg} / \mathrm{dia})$; $\mathrm{PF}=$ produção fecal estimada $(\mathrm{kg} / \mathrm{dia}) ; \mathrm{CIFZ}=$ concentração do indicador presente nas fezes $(\mathrm{kg} / \mathrm{kg})$; IS = indicador presente no suplemento $(\mathrm{kg} / \mathrm{dia})$; CIFR = concentração do indicador presente na forragem $(\mathrm{kg} / \mathrm{kg})$; e o CMSS = consumo de matéria seca do suplemento (kg/dia).

Os teores de matéria seca (MS), proteína bruta (PB), extrato etéreo (EE), fibra em detergente neutro (FDN) e fibra em detergente ácido (FDA) foram determinados em todas as amostras, conforme metodologias descritas por Silva \& Queiroz (2002).

O comportamento animal foi avaliado visualmente por um observador treinado para cada tratamento. As variáveis comportamentais estudadas foram os tempos de pastejo,

\begin{tabular}{|c|c|c|c|c|}
\hline \multirow[t]{2}{*}{ Item } & \multicolumn{4}{|c|}{ Nível de suplementação (\%) } \\
\hline & Capim-braquiária & 0,3 & 0,6 & 0,9 \\
\hline Matéria seca (\%) & 67,93 & 93,54 & 94,12 & 95,23 \\
\hline Extrato etéreo (\%) & 2,20 & 3,61 & 3,73 & 3,92 \\
\hline Carboidratos totais (\%) & 85,61 & 68,02 & 77,30 & 80,04 \\
\hline Carboidratos não-fibrosos (\%) & 1,31 & 55,78 & 64,37 & 66,68 \\
\hline Cinzas $(\%)$ & 6,10 & 5,88 & 3,36 & 2,74 \\
\hline Nutrientes digestíveis totais (\%) & 61,02 & 76,06 & 80,62 & 82,97 \\
\hline Disponibilidade total de matéria seca ( $\mathrm{kg} / \mathrm{ha})$ & 3654,84 & - & - & - \\
\hline Biomassa residual diária (kg de MS/ha/dia) & 130,53 & - & - & - \\
\hline Taxa de lotação (UA/ha) & 0,73 & - & - & - \\
\hline Taxa de acúmulo diário (kg MS/ha/dia) & 40,83 & - & - & - \\
\hline
\end{tabular}
ruminação, ócio e cocho. As observações foram realizadas com o auxílio de binóculos a uma distância aproximada de

Tabela 2 - Composição nutricional do capim-braquiária e dos concentrados 
$150 \mathrm{~m}$. As atividades comportamentais foram consideradas mutuamente excludentes, conforme definição de Pardo et al. (2003). Para o registro do tempo gasto em cada uma das atividades descritas acima, os animais foram observados visualmente a cada $10 \mathrm{~min}$ (Silva et al., 2006a), por dois períodos de $12 \mathrm{~h}$ cada (Silva et al., 2005) realizados no mês de setembro de 2006. A média do número de mastigações merícicas por bolo ruminal (MBR), do tempo gasto para ruminação de cada bolo (TBR) e o número de bolos ruminados (NBR) no período diurno foram obtidos registrando-se com cronômetros digitais nove valores por animal, conforme metodologia descrita por Burger et al. (2000). O tempo de mastigação total (TMT) foi determinado pela soma entre o tempo de pastejo e o tempo de ruminação.

A discretização das séries temporais foi realizada diretamente nas planilhas de coleta de dados, com a contagem dos períodos discretos de pastejo, ruminação, ócio e cocho, conforme descrito por Silva et al. (2006b). A duração média de cada um dos períodos discretos foi obtida pela divisão dos tempos diários de cada uma das atividades pelo número de períodos discretos. Em todas as variáveis comportamentais, um animal representou uma unidade experimental.

Os resultados foram interpretados estatisticamente por meio de análises de variância e regressão, utilizando-se o Sistema de Análises Estatísticas e Genéticas - SAEG (UFV, 1997). Os critérios adotados para escolha do modelo foram o coeficiente de determinação, calculado como a relação entre a soma de quadrados da regressão e a soma de quadrados de tratamentos; e a significância observada dos coeficientes de regressão, por meio do teste $\mathrm{F}$, conforme o modelo:

$$
\text { Yijk }=\mu+\mathrm{Ti}+\text { eijk: }
$$

Yijk - o valor observado da variável; $\mu$ - constante geral; $\mathrm{Ti}$ - efeito do tratamento i; eijk - erro associado a cada observação.

\section{Resultados e Discussão}

Houve efeito quadrático $(\mathrm{P}<0,05)$ da inclusão do concentrado na dieta total sobre os tempos de pastejo. No nível de suplementação de $0,6 \%$, ocorreu uma regulação do consumo voluntário e consequente redução do tempo de pastejo promovida pelo maior aporte ruminal de amônia oriunda da ureia que, neste tratamento, foi de $5 \%$ no concentrado (Tabela 1). O ponto de mínima estimado pela equação de regressão ocorreu no nível de 0,62\% de suplementação com 289 min de pastejo. Pardo et al. (2003) observaram que os animais pastejavam durante 66 , 48 e $44 \%$ do tempo diurno, quando receberam $0,0,75$ e $1,5 \%$ do PV em suplemento. No presente trabalho, esse valor variou de $58 \%$ a 41\%. Esses resultados são contrários aos relatos de Fischer et al. (2002), que verificaram redução linear dos tempos de pastejo em função do aumento dos níveis de suplementação. Bomfim et al. (2001) trabalharam com animais de 30 meses de idade observados durante $12 \mathrm{~h}$ (das 05h30 às 17h30) e não verificaram efeitos dos níveis de suplementação (0,6, 0,9, 1,2 e 1,5\% do PV) sobre os tempos de pastejo (386,25; 366,00; 346,25 e 315,00 min).

A ruminação não foi afetada $(\mathrm{P}<0,05)$ pelos níveis de suplementação. Dados semelhantes foram encontrados por Silva et al (2005), no qual relatam que os tempos de ruminação não sofreram efeito dos níveis de suplementação testados e encontraram a média de 158,91 min. Falcão et al. (1997), trabalhando com novilhas mestiças Holandês em pastagem de capim-elefante, verificaram que os animais passaram em média 153,29 min do período diurno ruminando, média esta próxima aos resultados encontrados no presente experimento.

Os tempos de ócio sofreram efeito quadrático $(\mathrm{P}<0,05)$ dos níveis de suplementação. De maneira inversa ao ocorrido com os tempos de pastejo e ruminação, os níveis de suplementação a 0,6 e $0,9 \%$ do peso vivo resultaram em tempos de ócio mais elevados, uma vez que as atividades

Tabela 3 - Tempos em pastejo, ruminação e ócio e tempo no cocho, em minutos, com suas respectivas equações de regressão e coeficientes de determinação $\left(\mathrm{r}^{2}\right)$

\begin{tabular}{|c|c|c|c|c|c|c|}
\hline \multirow[t]{2}{*}{ Atividade } & \multicolumn{4}{|c|}{ Nível de suplementação (\%) } & \multirow[t]{2}{*}{ Regressão } & \multirow[t]{2}{*}{$\mathrm{r}^{2}$} \\
\hline & 00 & 03 & 06 & 09 & & \\
\hline Pastejo & 425,0 & 292,5 & 320,0 & 305,5 & $\hat{Y}=414,900-405,333 x+327,778 x^{2}$ & 0,81 \\
\hline Ruminação & 132,0 & 97,5 & 126,5 & 95,5 & $\hat{Y}=112,87$ & - \\
\hline Ócio & 158,0 & 291,5 & 240,5 & 278,0 & $\hat{Y}=171,650+343,000 x-266,667 x^{2}$ & 0,66 \\
\hline Cocho & 5,0 & 38,5 & 33,0 & 41,0 & $\hat{Y}=7,625+9,791 x-0,708 x^{2}$ & 0,83 \\
\hline
\end{tabular}


comportamentais são mutuamente excludentes. O ponto de máxima estimado pela equação de regressão ocorreria a 0,64\% de suplementação com um tempo de ócio estimado de $282 \mathrm{~min}$. Silva et al. (2005) verificaram efeito linear decrescente sobre os tempos diurnos de ócio e o atribuiu ao aumento do tempo de permanência no cocho sem alterar o período de pastejo, o que posteriormente poderia ser compensado com maior tempo de ócio à noite. Os resultados encontrados estão em consonância com os relatos de Pardo et al. (2003), que verificaram menores tempos de descanso para animais não-suplementados. Esses mesmos autores deduzem que tal comportamento acontece em decorrência de menor tempo de pastejo, pelo provável menor consumo da forragem pelos animais suplementados, sobretudo, nos níveis mais elevados de suplementação. Fischer et al. (2002) relataram que animais recebendo 0 e $1 \%$ do $P V$ em concentrado permaneceram em ócio em média por 157 e 210 min, respectivamente.

Os tempos de permanência no cocho sofreram efeito quadrático $(\mathrm{P}<0,05)$. Neste item, merece destaque o fato de que a presença da ureia mais elevada no S03 fez com que os animais deste apresentassem interrupções no consumo do concentrado em virtude da consequente diminuição da palatabilidade do suplemento (Huber \& Cook, 1972) ou da associação feita pelos animais do desconforto pelo excesso de amônia formado e pelo gosto da ureia (Chalupa et al., 1979). Esses autores observaram redução da taxa de ingestão nos animais suplementados com ureia. Os animais consumiam o concentrado, bebiam água, e logo em seguida permaneciam alguns minutos em ócio antes de voltarem ao cocho para consumir mais concentrado. Por este fato, o nível de suplementação a $0,3 \%$ promoveu resultados superiores aos obtidos com o nível de $0,6 \%$, por exemplo, em que os animais consumiram o dobro da quantidade de suplemento.

Não houve efeito $(\mathrm{P}>0,05)$ dos níveis de suplementação testados sobre o consumo de matéria seca total (em kg/dia e em \% PV). Os consumos totais de matéria seca da pastagem (em kg/dia e em \% PV), os consumos de fibra em detergente neutro e fibra em detergente ácido tanto em quantidade como percentual do peso sofreram efeito linear decrescente $(\mathrm{P}<0,05)$. Esses resultados demonstram a ocorrência do efeito substitutivo com a inclusão dos níveis de concentrado; os dados de consumo permitem entender todas alterações comportamentais visualizadas neste estudo, já que o fornecimento de doses elevadas de suplemento pode acarretar depressão no $\mathrm{pH}$ ruminal, diminuindo a atividade de bactérias celulolíticas, o que pode resultar em decréscimo da digestão da fibra e no consumo de forragem via pastejo.Como pode ser observado, somente o nível de suplementação de 0,3\% não promoveu redução do consumo de forragem, enquanto nos níveis 0,6 e $0,9 \%$ foram obtidos ganhos inferiores ao esperado.

Segundo El-Memari Neto et al. (2003), a elevação do teor de carboidratos não-estruturais na dieta fornece mais substrato aos microrganismos produtores de propionato. Com isso, ocorrerá maior produção total de ácidos graxos voláteis, bem como maior produção de lactato, o que pode acarretar diminuição do pH ruminal (Russel, 1998). Este acúmulo de ácidos no rúmen pode causar danos ao epitélio ruminal e inibir a atividade dos microrganismos celulolíticos (Orskov et al., 1971), podendo ter como consequência a redução da ingestão de forragem e resultante diminuição do consumo de MS total pela redução na digestibilidade da fibra (Grant, 1994). Os resultados referentes aos dados de consumo obtidos no presente experimento corroboram as

Tabela 4 - Ganho médio diário e consumo de matéria seca (MS), fibra em detergente neutro (FDN) e fibra em detergente ácido (FDA), totais ou da pastagem

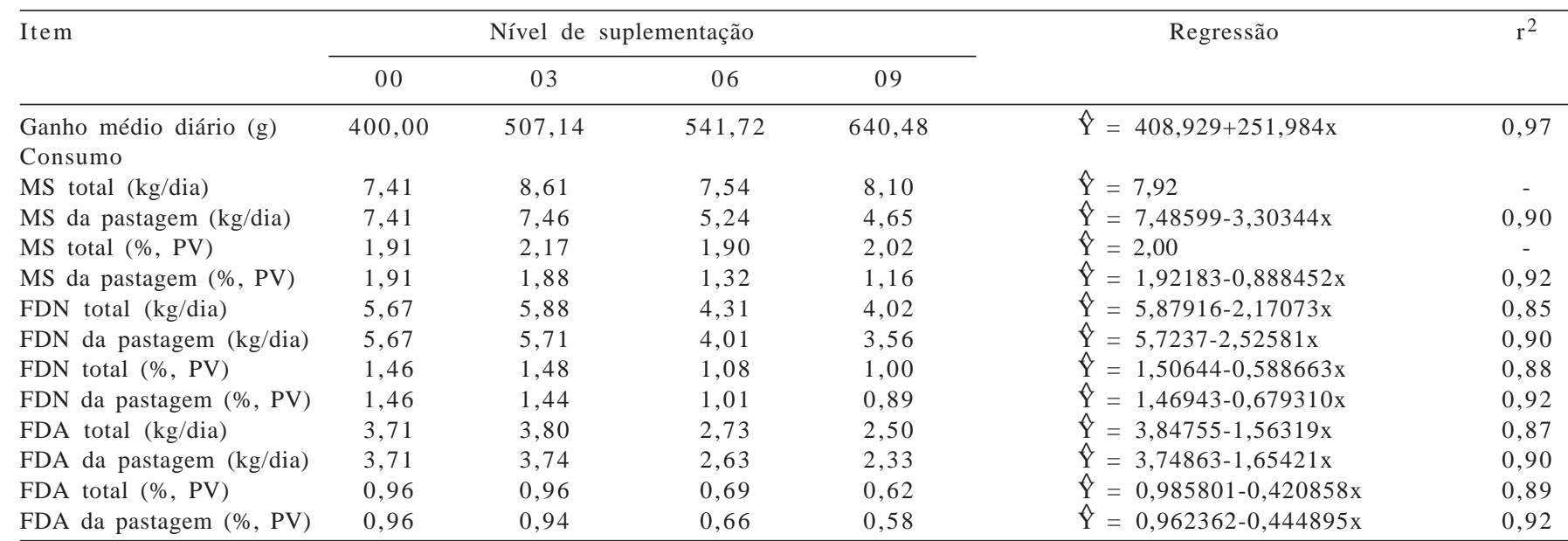


constatações relatadas na literatura, uma vez que, a partir do ponto de máximo consumo, com interações aditivas, há diminuição, sendo esta provavelmente resultado da interface forragem:suplemento:animal, apontando efeitos redutores de consumo relacionados à elevação do nível de suplementação (El-Memari Neto et al., 2003).

Não houve efeito $(\mathrm{P}>0,05)$ dos níveis de suplementação testados sobre o tempo de mastigação total, o número de bolos ruminados no período de 12 horas e o tempo gasto para ruminação de cada bolo. Os resultados encontrados no presente estudo no que se refere ao tempo de mastigação total estão em desacordo com a teoria de Dulphy et al. (1980) ao afirmar que, com a elevação dos níveis de concentrado na dieta total e consequente aumento do teor de amido, haveria uma diminuição do tempo de mastigação total. Em coletânea com resultados de 32 experimentos, Allen (1997) encontrou valor médio diário para o tempo de mastigação total de 667,80 min. Logicamente, por se tratar de um período de 24 horas, estes resultados são superiores aos encontrados no presente experimento, uma vez que, neste, o tempo de mastigação total foi determinado apenas no período diurno. Como os bovinos apresentam hábito de pastejo diurno, e levando-se em consideração esses resultados, estima-se que o tempo de mastigação total diurno representa em média de $65 \%$ a $85 \%$ do tempo de mastigação total. Recentes estudos enfatizam a possibilidade do ajuste do comportamento referente ao pastejo em função da disponibilidade de forragem, o que em áreas com elevada quantidade de MS/ha permite um pastejo mais eficiente (Silva et al., 2007). Silva et al. (2005) não observaram efeito de quatro níveis de suplementação que variaram de $0,25 \%$ a 1,00\% sobre o tempo de mastigação total, número de bolos ruminados e total de bolos ruminados. Os valores relatados para essas três variáveis foram 640,0 min, 272 bolos e de 36 segundos por bolo, respectivamente.

O número de mastigações merícicas por bolo ruminado sofreu efeito linear decrescente $(\mathrm{P}<0,05)$. Silva et al. (2005) também verificaram efeito linear decrescente cujos valores foram 44, 44, 43 e 37 mastigações por bolo para os níveis de 0,25; 0,50; 0,75 e 1,00\% de suplementação do peso vivo. Vale salientar que, apesar de categorias e grupos genéticos distintos, os resultados são semelhantes, o que permite estabelecer uma linha de comparações. Neste estudo, determinou-se que o decréscimo das mastigações merícicas por bolo ruminado deve-se à diminuição do consumo de FDN.

O número de períodos de pastejo sofreu efeito linear crescente $(P<0,05)$ em função dos níveis de suplementação. Estes resultados corroboram os observados por Moreno et al. (2008), o quais verificaram aumento no NPP de 7,6 para 8,5, respectivamente, para animais sem suplementação e com suplementação. Em decorrência deste comportamento do NPP, houve reflexo no TPP, que apresentou efeito linear decrescente $(\mathrm{P}<0,05)$.

Os números de períodos de pastejo e ócio sofreram efeito quadrático $(\mathrm{P}<0,05)$. Os pontos de máxima estimados foram 5,80 e 8,98 aos níveis de 0,42 e $0,62 \%$ de suplementação para NPR e NPO, respectivamente. O comportamento destas duas variáveis deve-se, primariamente, ao efeito aditivo da suplementação que se declina a partir dos pontos de máxima por todas alterações do metabolismo ruminal estabelecidas

Tabela 5 - Tempo de mastigação total, quantidade de bolos ruminados, tempo gasto/bolo, número de mastigações/bolo ruminado

\begin{tabular}{lcccccr}
\hline Atividade & \multicolumn{3}{c}{ Nível de suplementação (\%) } & \multirow{2}{*}{ Regressão } \\
\cline { 2 - 5 } & 00 & 03 & 06 & 09 & $\mathrm{r}^{2}$ \\
\hline Tempo de mastigação total (minutos/12 horas) & 562 & 429 & 480 & 442 & $\hat{Y}=478,25$ & - \\
Bolos/12 horas & 193 & 154 & 180 & 164 & $\hat{Y}=172,75$ & - \\
Tempo/bolo (segundos) & 41 & 38 & 42 & 35 & $\hat{Y}=39$ & $\hat{Y}=47,50-10,00 x$ \\
Mastigações/bolo & 47 & 44 & 44 & 37 & 0,83 \\
\hline
\end{tabular}

Tabela 6 - Números de períodos e tempo de duração das atividades comportamentais

\begin{tabular}{lcccccc}
\hline & \multicolumn{3}{c}{ Nível de suplementação (\%) } & & \multirow{2}{*}{ Regressão } \\
\cline { 2 - 5 } & 0,0 & 0,3 & 0,6 & 0,9 & & \\
\hline Períodos em pastejo & 5,90 & 6,50 & 6,75 & 7,25 & $\hat{Y}=5,95500+1,433333 x$ \\
Períodos em ruminação & 4,60 & 5,55 & 5,70 & 4,05 & $\hat{Y}=4,5500+6,0000 x-7,22222 x^{2}$ & 0,95 \\
Períodos em ócio & 5,45 & 9,05 & 8,05 & 8,60 & $\hat{Y}=5,7575+10,4417 x-8,47222 x^{2}$ & 0,64 \\
Períodos comendo no cocho & 0,50 & 2,50 & 1,00 & 1,50 & $\hat{Y}=0,50+18,61 x-50,00 x^{2}+33,95 x^{3}$ & 1,00 \\
Tempo de pastejo (min) & 72,45 & 46,95 & 49,44 & 42,48 & $\hat{Y}=65,9405-29,1313 x$ & 0,63 \\
Tempo em ruminação (min) & 28,70 & 17,45 & 22,01 & 24,51 & $\hat{Y}=27,8053-37,092 x+38,1972 x^{2}$ & 0,62 \\
Tempo em ócio (min) & 28,64 & 33,17 & 30,27 & 32,53 & $\hat{Y}=31,16$ & - \\
Tempo no cocho (min) & 10,00 & 15,40 & 33,00 & 28,17 & $\hat{Y}=10,8264+24,0347 x$ & 0,73 \\
\hline
\end{tabular}


para níveis mais elevados de concentrado na dieta total. O número de período comendo no cocho sofreu efeito cúbico $(P<0,05)$. Esses resultados podem ser atribuídos às mesmas causas relacionadas na discussão do tempo de permanência do cocho observado com o fornecimento do nível 0,3\% de concentrado (do concentrado do S03).

O tempo de duração dos períodos de pastejo apresentaram efeito quadrático $(\mathrm{P}<0,05)$ com ponto de mínima estimado em 18,80 min para o nível de 0,49\% de suplementação. Pereira et al. (2005), fornecendo diferentes suplementos ao nível de 0,75 \% do PV não relataram efeito sobre o tempo de duração dos períodos de ruminação e encontraram valor médio de 27,56 min. O tempo de duração dos períodos de ócio não foi afetado $(\mathrm{P}>0,05)$ pelos níveis de suplementação. Esses resultados corroboram os relatos de Silva et al. (2005), que também não encontraram efeito da suplementação sobre esta variável. Entretanto, os valores $(10,47)$ relatados por esses autores são inferiores aos do presente estudo. O tempo de duração dos períodos de cocho sofreu efeito linear crescente $(\mathrm{P}<0,05)$ em função dos níveis de suplementação. Resultados semelhantes foram relatados por Silva et al. (2005). Entretanto, os valores relatados foram bem inferiores aos do presente experimento e variaram de 6,56 a 13,85 min por período.

\section{Conclusões}

A suplementação altera o comportamento ingestivo diurno, não só pela quantidade de alimento ingerida, mas também por sua composição e razão volumoso:concentrado.

\section{Referências}

ALBRIGHT, J.L. Nutrition, feeding and calves: feeding behavior of dairy cattle. Journal of Dairy Science, v.76, p.485-498, 1993.

ALLEN, M.S. Relationship between fermentation acid production in the rumen and the requirement for physically effective fiber. Journal of Dairy Science, v.80, p.1447-1462, 1997.

BERCHIELLI, T.T. Nutrição de ruminantes. Jaboticabal: FUNESP, 2006. 583p.

BOMFIM, M.A.D.; REZENDE, C.A.P.; PAIVA, P.C.A. et al. Níveis de concentrado na engorda de novilhos Holandês x Zebu suplementados a pasto na estação seca do ano. Ciência e Agrotecnologia, v.25, n.6, p.1457-1466, 2001.

BRÂNCIO, P.A.; EUCLIDES, V.P.B.; NASCIMENTO JR., D. et al. Avaliação de três cultivares de Panicum maximum Jacq. Sob pastejo: Comportamento ingestivo de bovinos. Revista Brasileira de Zootecnia, v.32, n.5, p.1045-1053, 2003.

BURGER P.J.; PEREIRA J.C.; QUEIROZ, A.C. et al. Comportamento ingestivo de bezerros holandeses alimentados com dietas contendo diferentes níveis de concentrado. Revista Brasileira de Zootecnia, v.29, p.236-242, 2000.

CAMPBELL, A.G. Grazed pastures parameters: I. Pasture dry matter production and availability in a stocking rate and grazing management experiment with dairy cows. Journal of Agriculture Science, v.67, p.211-216, 1996.

CHALUPA, W.; CLIFTON, A.B.; MCLAUGHLIN, C.L. et al. Effect of introduction of urea on feeding behavior of Holstein heifers. Journal of Dairy Science, v.62, n.10, p.1278-1284, 1979.

DULPHY, J.P. Ingestive behaviour and related activities in ruminants. In: RUCKEBUSH, Y.; THIVEND, P. (Eds.) Digestive physiology and metabolism. Lancaster: MTP, 1980. p.103-122.

EL-MEMARI NETO, A.C.; ZEOULA, L.M.; CECATO, U. et al. Suplementação de novilhos Nelore em pastejo de Brachiaria brizantha com diferentes níveis e fontes de concentrado. Revista Brasileira de Zootecnia, v.32, n.6, p.1945-1955, 2003 (supl. 2).

FALCÃO, J.F.N. Comportamento de novilhas leiteiras da raça Holandesa em pastagem de capim elefante. In: REUNIÃO ANUAL DA SOCIEDADE BRASILEIRA DE ZOOTECNIA, 34., 1997, Juiz de Fora. Anais... Juiz de Fora: Sociedade Brasileira de Zootecnia, 1997. p.252-255.

FISCHER, V.; DESWYSEN, A.G.; DUTILLEUL, P. et al. Padrões da distribuição nictemeral do comportamento ingestivo de vacas leiteiras, ao inicio e ao final da lactação, alimentadas com dieta à base de silagem de milho. Revista Brasileira de Zootecnia, v.31, n.5, p.2129-2138, 2002.

GARDNER, A.L. Técnicas de pesquisa em pastagem e aplicabilidade de resultados em sistema de produção. Brasília: IICA/EMBRAPA CNPGL, 1986. 197p.

GRANT, J.J. Influence of corn and sorghum starch on the in vitro kinetics of forage fiber digestion. Journal of Dairy Science, v.76, p.2102-2111, 1994.

HUBER, J.T.; COOK, R.M. Influence of site administration of urea on voluntary intake of concentrate by lactating cows. Journal of Dairy Science, v.55, n.10, p.1470-1473, 1972.

KABEYA, K.S.; PAULINO, M.F.; VALADARES FILHO, S.C. et al. Suplementação de novilhos mestiços em pastejo na época de transição água-seca: desempenho produtivo, características físicas de carcaça, consumo e parâmetros ruminais. Revista Brasileira de Zootecnia, v.31, n.1, p.213-222, 2002.

McMENIMAN, N.P. Methods of estimating intake of grazing animals. In: REUNIÃO ANUAL DA SOCIEDADE BRASILEIRA DE ZOOTECNIA, SIMPÓSIO SOBRE TÓPICOS ESPECIAIS EM ZOOTECnIA, 34., 1997, Juiz de Fora. Anais... Juiz de Fora: Sociedade Brasileira de Zootecnia, 1997. p.131-168.

MORENO, C.B.; FISCHER, V.; MONKS, P.L. et al. Comportamento ingestivo diurno de novilhas Jersey sob suplementação com farelo de milho em pastagem de azevém anual. Revista Brasileira de Zootecnia, v.37, n.3, p.487-493, 2008.

ØRSKOV, E.R. The nutrition of the early weaned lamb. 3. The effect of ad libitum intake of diets varying in protein concentration on performance and on body composition at different live weights. Journal of Agriculture Science, v.77, p.351-361, 1971.

PARDO, R.M.P.; FISCHER, V.; BALBINOTTI, M. et al. Comportamento ingestivo diurno de novilhos em pastejo a níveis crescentes de suplementação energética. Revista Brasileira de Zootecnia, v.32, p.1408-1418, 2003.

PEREIRA, L.M.R.; FISCHER, V.; MORENO, C. et al. Comportamento ingestivo diurno de novilhas Jersey em pastejo recebendo diferentes suplementos. Revista Brasileira Agrociência, v.11, n.4, p.453-459, 2005.

PROHMANN, P.E.F.; BRANCO, A.F.; CECATO, U. et al. Suplementação de bovinos em pastagens de Coastcross (Cynodon dactylon (L.) Pers) no inverno. Revista Brasileira de Zootecnia, v.33, n.4, p.801-810, 2004.

ROCHA, M.G. Suplementação a campo de bovinos de corte. In: LOBATO, J.F.P. (Ed.). Produção de bovinos de corte. Porto Alegre: PUCRS, 1999. p.77-96. 
RUSSEL, J.B. Estrategies that ruminal bacteria use to handle excess carbohydrate. Journal of Animal Science, v.76, p.1955-1963, 1998.

SILVA, D.J.; QUEIROZ, A.C. Análise de alimentos (métodos químicos e biológicos). Viçosa, MG: Universidade Federal de Viçosa, 2002. 235p.

SILVA, R.R.; CARVALHO, G.G.P.; MAGALHÃES, A.F. et al. Comportamento ingestivo de novilhas mestiças de holandês em pastejo. Archivos de Zootecnia, v.54, p.63-74, 2005.

SILVA, R.R.; PRADO, I.N.; CARVALHO, G.G.P. et al. Efeito da presença do bezerro sobre o comportamento ingestivo de vacas leiteiras em pastejo de Brachiaria decumbens. Revista Brasileira de Saúde e Produção Animal, v.8, p.48-55, 2007.

SILVA, R.R.; SILVA, F.F.; PRADO, I.N. et al. Metodologia para o estudo do comportamento de bezerros confinados na fase pósaleitamento. Archivos Latinoamericanos de Producción Animal, v.42, p.135-138, 2006a.
SILVA, R.R.; SILVA, F.F.; PRADO, I.N. et al. Comportamento ingestivo de bovinos. Aspectos metodológicos. Archivos de Zootecnia, v.55, p.293-296, 2006b.

SNIFFEN, C.J.; O'CONNOR, J.D.; VAN SOEST, P.J. et al. A net carbohydrate and protein system for evaluating cattle diets: II- Carbohydrate and protein availability. Journal of Dairy Science, v.70, p.3562-3577, 1992.

UNIVERSIDADE FEDERAL DE VIÇOSA - UFV. Sistema de Análises Estatísticas e Genéticas - SAEG. Versão 8.0. Viçosa, MG, 2000. 142p.

WILLIANS, C.H.; WILLIAMS, C.H.; DAVID, D.J. et al. The determination of cromic oxide in faeces samples by atomic absorption spectrophotometry. Journal of Agriculture Science, v.59, p.381-385, 1962.

WILM, H.G.; COSTELLO, D.F.; KLIPPLE, G.E. Estimating forage yield by the double sampling method. Journal of the American Society of Agronomy, v.36, p.194-203, 1994. 